\title{
SEGURANÇA NA RECUPERAÇÃO DAS ESTRUTURAS DE CONCRETO DE UMA SUBESTAÇÃO 230KV*
}

Robson Gambeta ${ }^{1}$

\section{Resumo}

A CLE Brasil possui uma subestação de 230kV que apresentou sérios problemas de trincas e rachaduras nas estruturas de concreto após alguns anos. Em alguns pontos a ameaça de queda era real. Foi iniciado um estudo de patologia das estruturas de concreto, com uma empresa especializada em recuperação estrutural para conhecer as causas e recomendar a melhor terapia estrutural a ser realizada. Após o estudo, definiu-se a terapia adequada das estruturas. Esta atividade foi classificada como de grande risco e teve foco na segurança da equipe e operação do sistema, de modo que todo o serviço fosse executado sem quaisquer incidentes as pessoas, ao meio ambiente e ou interrupções de energia elétrica. Havia desafios como realizar manutenção nas proximidades da linha viva, serviços em altura com utilização de andaimes, período de chuvas e ventos, trocas de equipes e anomalias. As estruturas tratadas foram Pórticos com 17 metros de altura, postes e suportes para isoladores, TPs, TCs, Seccionadoras e Transformadores. A atividade durou 04 meses e contabilizou 5.752 horas de trabalho. Os resultados foram significativos e dentro do esperado, sem ocorrência de incidentes, prolongamento da vida útil e aumento considerável da segurança da equipe e do sistema de distribuição.

Palavras-chave: Terapia estrutural; Segurança; Manutenção; Vida útil.

\section{SAFETY IN THE CONCRETE STRUCTURES RECOVERY OF A 230KV SUBSTATION}

\section{Abstract}

CLE Brazil has a $230 \mathrm{kV}$ substation which presented serious problems of cracks and disruptions in the concrete structures after a few years. At some points the threat of falling was real. A study of pathology of concrete structures with a company specialized in structural repair was initiated to know the causes and recommend the best structural therapy to be performed. After the study, it was defined the appropriate structures therapy. This activity was classified as high risk and had the team focus on safety and operation of the system, so that all the work was carried out without any incidents to people, to the environment and or power outages. There were challenges such as performing maintenance near the live line, services in height with use of scaffolding, period of rains and winds, team exchanges and anomalies. The structures were Porches with 17 meters height, poles and brackets for insulators, TPs, TCs, transformers and disconnectors. The activity lasted 04 months and recorded 5752 hours of work. The results were significant and as expected, without any incidents, life extension and substantial increase in staff safety and the distribution system.

Keywords: Structural therapy; Safety; Maintenance; Life extension.

1 Engenharia Elétrica, Engenheiro Eletricista, Especialista em Processos Elétricos, Departamento de Engenharia de Processos, CLE Brasil Veolia, São Francisco do Sul, Santa Catarina, Brasil.

* Contribuição técnica ao $35^{\circ}$ Seminário de Balanços Energéticos Globais e Utilidades e $29^{\circ}$ Encontro de Produtores e Consumidores de Gases Industriais, 13 a 15 de agosto de 2014, São Paulo, SP, Brasil. 


\section{INTRODUÇÃO}

Este trabalho traz uma abordagem clássica e ao mesmo tempo inabitual sobre manutenção em subestações de alta tensão. A CLE Brasil possui uma subestação de 230kV construída no ano de 2002 que com o passar dos anos sofreu uma depreciação inesperada e preocupante. No ano de 2003 surgiu uma trinca na viga superior do Pórtico de entrada da Linha 02 (existem duas entradas sendo 01 e 02). Com o surgimento da trinca, veio o primeiro alerta sobre uma possível patologia que estaria se instalando ou má qualidade na fabricação dos postes.

A partir de 2003, criou-se a rotina de inspecionar a trica do Pórtico 02 nas preventivas bienais posteriormente realizadas para o devido acompanhamento.

Anos mais tarde notou-se também a deterioração prematura das estruturas de concreto que sustentam os equipamentos do pátio da Subestação, surgindo a necessidade de um tratamento estrutural eficaz urgente.

Esta apresentação tem como objetivo principal, demonstrar a aplicação de métodos de Segurança na Recuperação das Estruturas de Concreto de uma Subestação $230 \mathrm{kV}$ priorizando incondicionalmente a segurança da equipe envolvida e do meio ambiente sem que houvesse interrupção no fornecimento de energia.

Esta atividade possuía uma serie de desafios a serem enfrentados de forma a garantir a segurança de todos, através das seguintes premissas: Conscientização da equipe sobre os riscos existentes no ambiente, Serviços com a Linha Viva sem invadir a Zona de Risco conforme NR-10 [1], Trabalhos em Altura NR-35[2], período de chuvas e rotatividade das equipes terceirizadas.

\section{MATERIAIS E MÉTODOS}

\subsection{Procedimentos de Segurança}

\subsubsection{Equipe técnica envolvida na atividade}

Desde o início das atividades a preocupação com a saúde e segurança de todos os envolvidos foi prioridade incondicional. Para assegurar que os procedimentos de segurança fossem cumpridos, foi disponibilizado em tempo integral um Técnico Eletricista Autorizado NR-10[1], um Técnico de Segurança de Trabalho e um Especialista em Processos Elétricos(Engenheiro Eletricista).

Também houve apoio externo com a contratação de um Técnico de Segurança de Trabalho da empresa fornecedora dos andaimes que acompanhou em tempo integral as montagens e desmontagens dos andaimes próximos a linha de $230 \mathrm{kV}$ energizada.

E por se tratar de uma manutenção especial, buscou-se apoio das empresas especializadas em serviços com eletricidade tais como Vivante e ABB.

\subsubsection{Procedimentos aplicados durante a obra}

Os procedimentos utilizados para garantir a segurança e andamento na execução das atividades foram:

- Integração do Condomínio e da CLE Brasil: focar os riscos com serviços nas proximidades da Alta Tensão;

- Dialogo Diário de Segurança (DDS): exemplificar e discutir diariamente os riscos e experiências ocorridas durante as atividades;

- Medição diária da Pressão Arterial e Alcoolemia: prevenir possíveis acidentes em altura decorrentes de mal estar físico ou ingestão de bebidas alcoólicas;

* Contribuição técnica ao $35^{\circ}$ Seminário de Balanços Energéticos Globais e Utilidades e $29^{\circ}$ Encontro de Produtores e Consumidores de Gases Industriais, 13 a 15 de agosto de 2014, São Paulo, SP, Brasil. 
- Permissão de Trabalho diária: informar todos os responsáveis das áreas envolvidas sobre as atividades naquele dia;

- Análise Preliminar de Riscos: avaliar cada tarefa e disponibilizando suas devidas medidas de prevenção coletiva e pessoal.

- Matrizes de Perigos e Riscos: informar os perigos e riscos das atividades mais rotineiras presentes na Subestação;

- Matrizes de Aspectos e Impactos Ambientais: listar todos os resíduos gerados e encaminhar a sua correta destinação;

- Diagramas unifilares e esquemas elétricos da Subestação; auxiliar nas manobras de linha e orientar a sequencia das atividades;

- Norma Reguladora NR-10: contribuir para a elaboração dos procedimentos de segurança como as Zonas de Risco, Controlada e Livre NR-10[1].

\subsubsection{Controle de anomalias}

Durante a execução das atividades foram apontadas e registradas 27 anomalias. Todas estas anomalias foram imediatamente solucionadas interrompendo a atividade e esclarecendo a solução para que não fosse reincidente. Além do reforço nos esclarecimentos das anomalias, o assunto era novamente abordado nos DDS dos dias seguintes.

\subsubsection{Respeito ao meio ambiente}

Antes de iniciar as atividades foi desenvolvida a Matriz de Aspectos e Impactos Ambientais para que fosse possível prever e identificar os resíduos a serem gerados na obra e definir sua correta destinação final, conforme vista na figura 1.

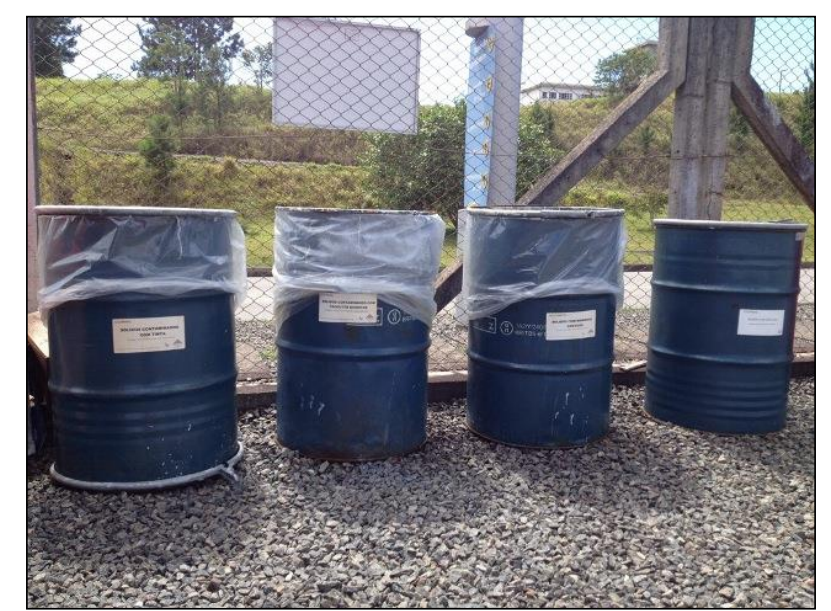

Figura 1: Segregação e Destinação correta dos Resíduos

Visando gerar o menor impacto ambiental possível, foram preservados os ninhos de pássaros com ovos que estavam na subestação, sem oferecer riscos à integridade das pessoas e do sistema. Alguns pássaros chocaram seus ovos durante a execução das atividades (Figura 2).

\footnotetext{
* Contribuição técnica ao $35^{\circ}$ Seminário de Balanços Energéticos Globais e Utilidades e $29^{\circ}$ Encontro de Produtores e Consumidores de Gases Industriais, 13 a 15 de agosto de 2014, São Paulo, SP, Brasil.
} 

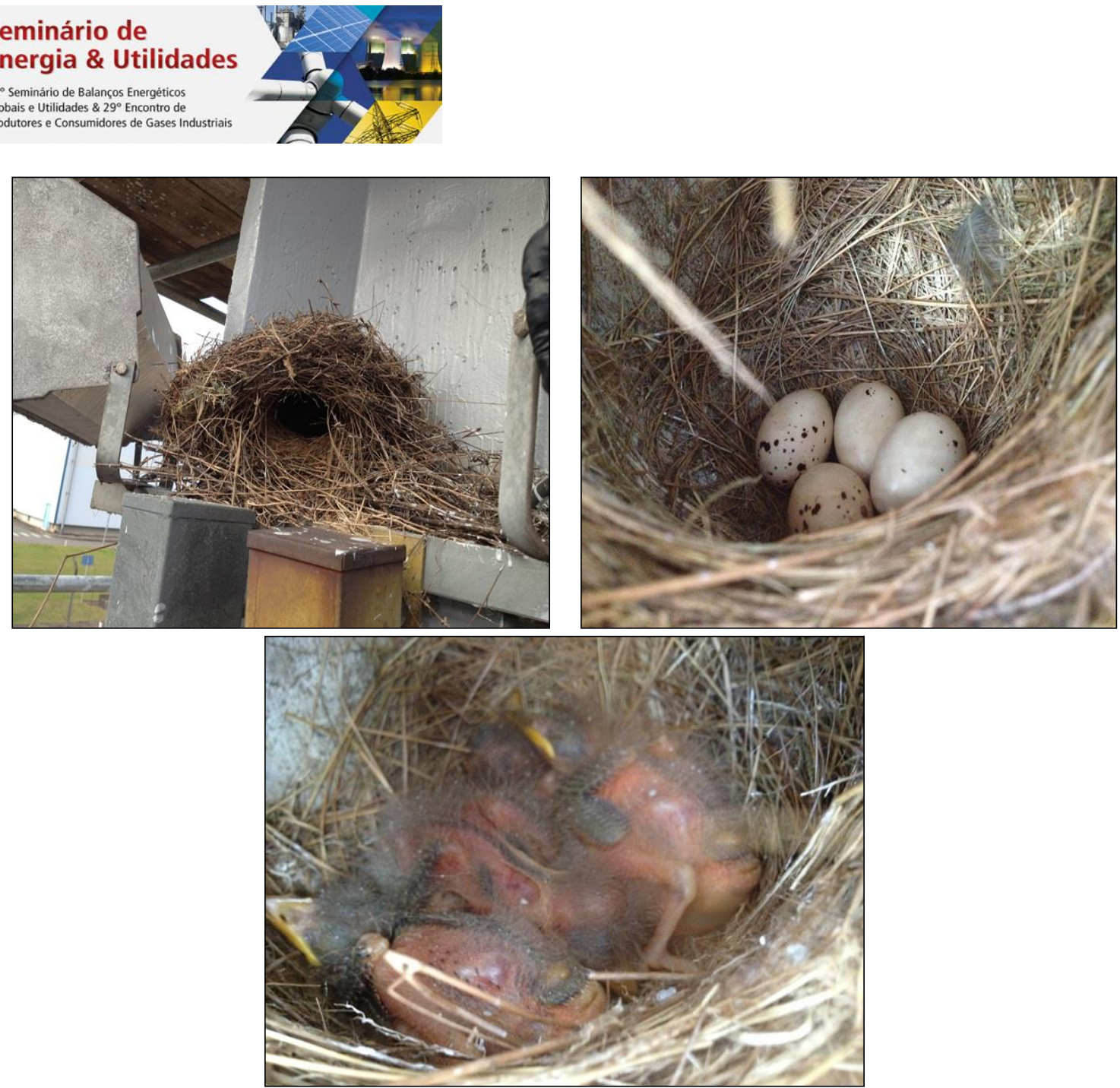

Figura 2. Acompanhamento da cria dos pássaros antes da remoção do ninho.

\subsection{Procedimentos das Atividades}

\subsubsection{Preparativos para a recuperação das estruturas de concreto}

O planejamento para iniciar as atividades consistiu primeiramente em calcular as distancias permitidas para trabalho na Zona Controlada NR-10 [1], de modo que a equipe de montagem dos andaimes e de recuperação estrutural não invadisse em momento algum a Zona de Risco. Este planejamento foi realizado por meio de consultas á documentos técnicos, desenhos, normas e medições em campo.

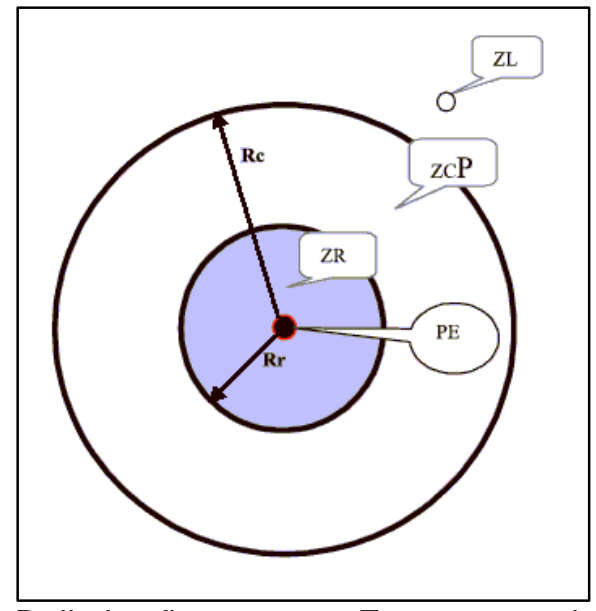

Figura 3: Delimitações entre as Zonas segundo a NR-10

* Contribuição técnica ao $35^{\circ}$ Seminário de Balanços Energéticos Globais e Utilidades e $29^{\circ}$ Encontro de Produtores e Consumidores de Gases Industriais, 13 a 15 de agosto de 2014, São Paulo, SP, Brasil. 


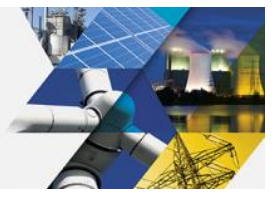

Através de um trabalho conjunto entre as equipes técnicas envolvidas, foi elaborado o dimensionamento das distâncias mínimas permitidas em todos os pontos a serem recuperados. Na figura 4 é possível verificar como foi realizada a analise das delimitações entre áreas de risco e controlada, delimitando assim a região de trabalho das equipes.
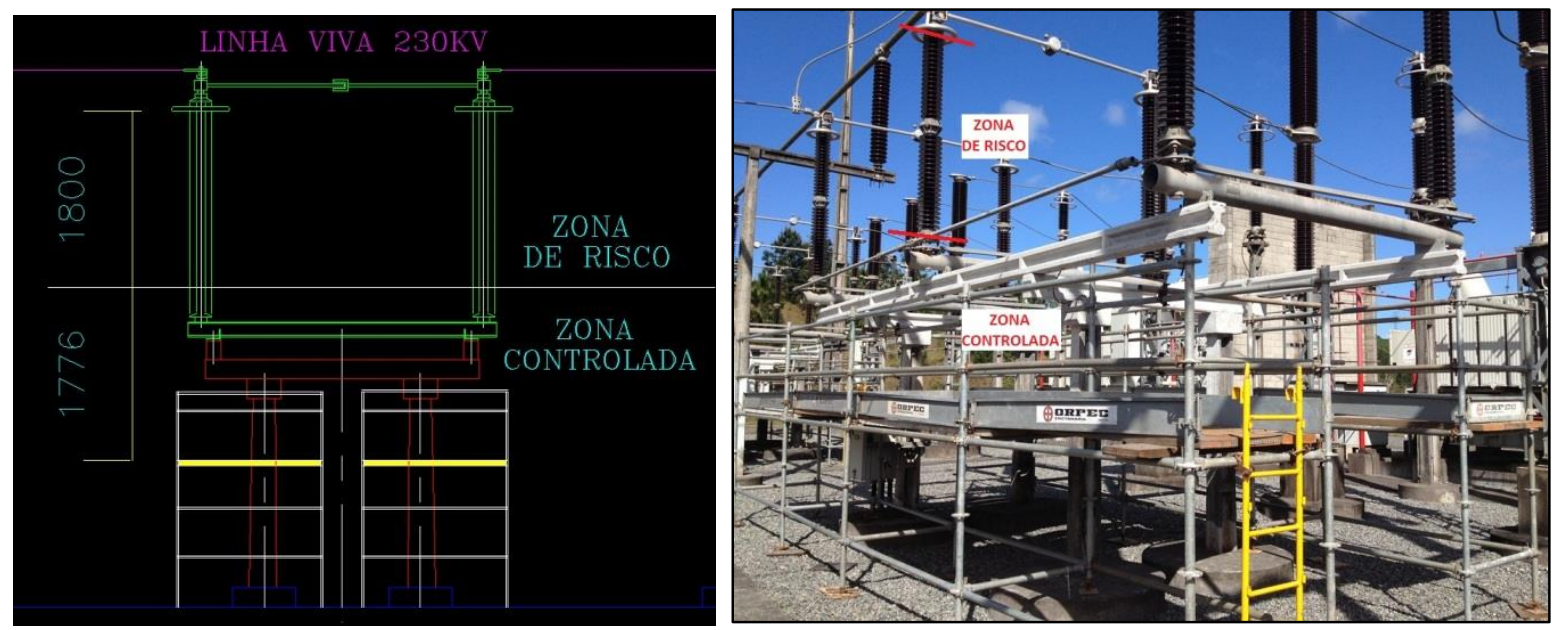

Figura 4: Planejamento das delimitações das Zonas. Delimitações das Zonas na prática

\subsubsection{Recuperação estrutural nos pórticos de entrada}

A Subestação $230 \mathrm{kV}$ é composta por duas linhas de entrada em alta tensão independentes sendo que ambas sofreram o processo de recuperação estrutural. A intervenção nas linhas de entrada foi realizada individualmente possibilitando 0 desligamento e bloqueio até o disjuntor de entrada. Com isso reduziu-se consideravelmente os riscos envolvidos.
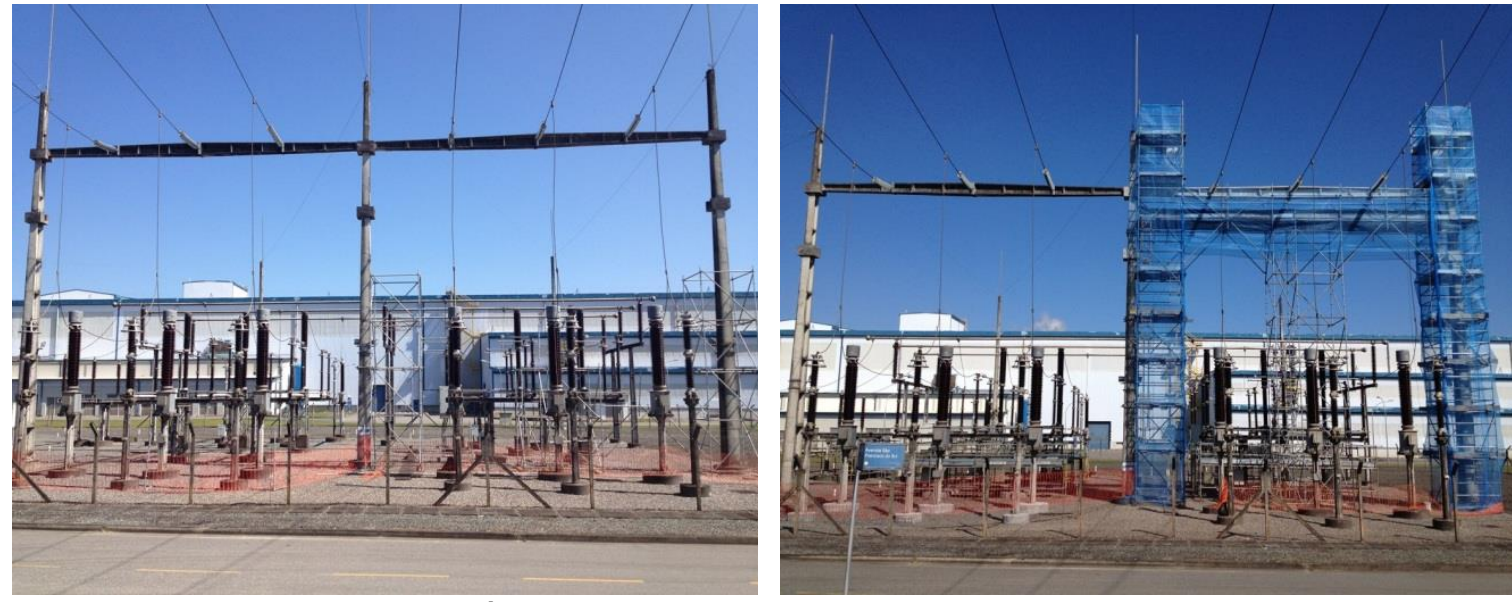

Figura 5: Pórtico de Entrada com as duas Linhas de 230kV

Após a liberação dos andaimes pela equipe de segurança, foi iniciada a atividade de recuperação estrutural deste pórtico, a fim de remover os ataques ao concreto e prolongar a vida útil da estrutura.

O procedimento da execução de recuperação a seguir foi aplicado ao restante das estruturas do pátio e por isso, não será repetido novamente.

O procedimento foi elaborado pela empresa especializada em recuperação estrutural e consiste nas seguintes atividades:

- Limpeza das estruturas do Pórtico;

* Contribuição técnica ao $35^{\circ}$ Seminário de Balanços Energéticos Globais e Utilidades e $29^{\circ}$ Encontro de Produtores e Consumidores de Gases Industriais, 13 a 15 de agosto de 2014, São Paulo, SP, Brasil. 


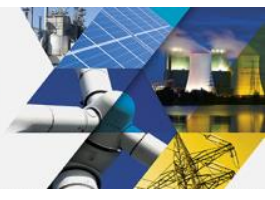

- Remoção do concreto atacado e limpeza das ferragens;

- Aplicação de Primer zinco nas ferragens para neutralizar oxidações;

- Reparos das trincas com Argamassa S88;

- Aplicação de resina Prime;

- Aplicação de resina Estruturante;

- Colocação das Micro-fibras de carbono 500 micro fios;

- Outra camada de resina Estruturante;

- Cura de 24 horas;

- Após boa cura, aplicação uma fina camada de Argamassa S88 para proteção das fibras contra intempéries;

- Primeira demão de tinta Prime Epox para vedar e isolar as estruturas da umidade;

- Realizado duas demãos de tinta de superfície PU(Poliuretano);

- Pórtico liberado para desmontagem dos andaimes e reenergização.
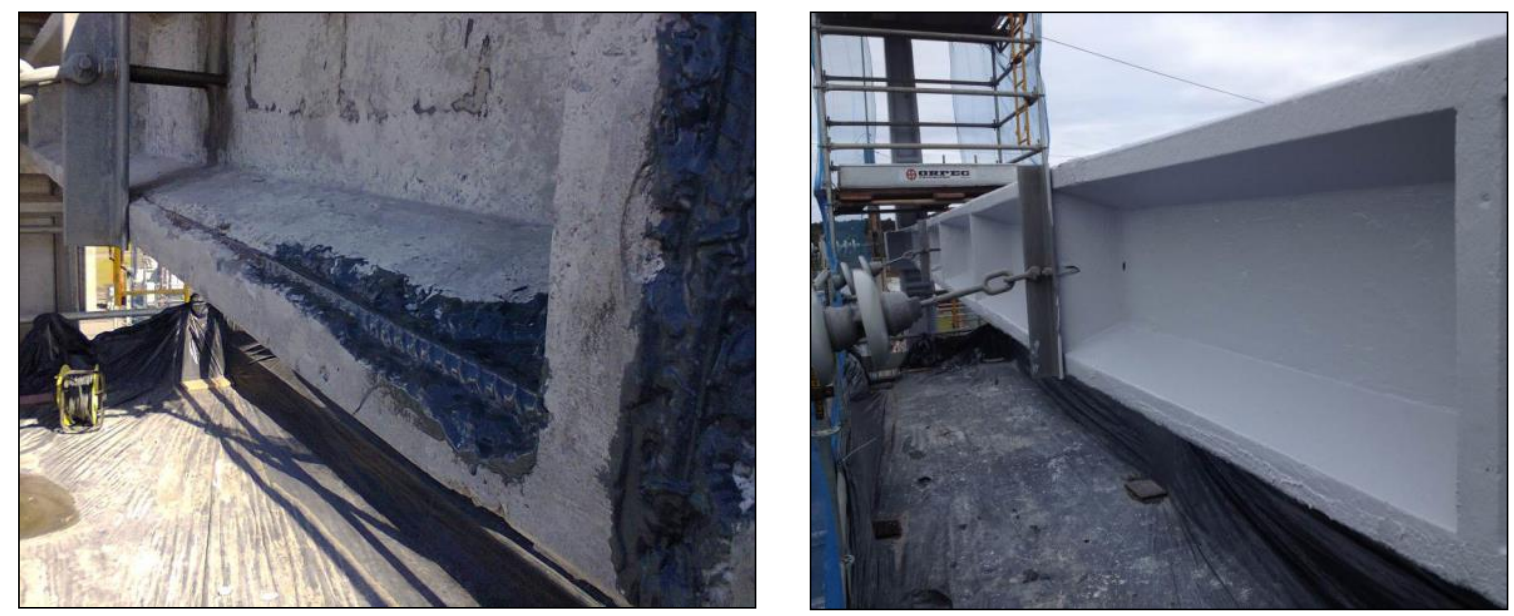

Figura 6: Pórtico de Entrada da Linha 01 sendo reparado

\subsubsection{Recuperação estrutural nos demais postes de sustentação}

Nos demais postes de sustentação de equipamentos da Subestação, os reparos seguiram o mesmo procedimento descrito no item 2.3.2 porém com a linha viva (Energizada) sobre a cabeça das equipes de montagem e recuperação.

Os planejamentos das distancias controladas entraram em ação mais intensamente nessa fase da manutenção porque não foi possível desenergizar toda a linha de 230kV o que levaria a parada da fábrica por dias.

Foram encontradas estruturas próximas ao colapso, exigindo o máximo de cuidado e técnica na montagem de suportes e andaimes para os reparos.

* Contribuição técnica ao $35^{\circ}$ Seminário de Balanços Energéticos Globais e Utilidades e $29^{\circ}$ Encontro de Produtores e Consumidores de Gases Industriais, 13 a 15 de agosto de 2014, São Paulo, SP, Brasil. 


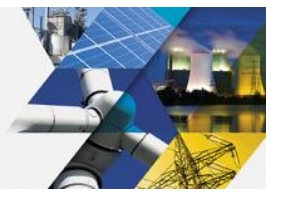

\subsubsection{Fotos de alguns postes a serem recuperados}
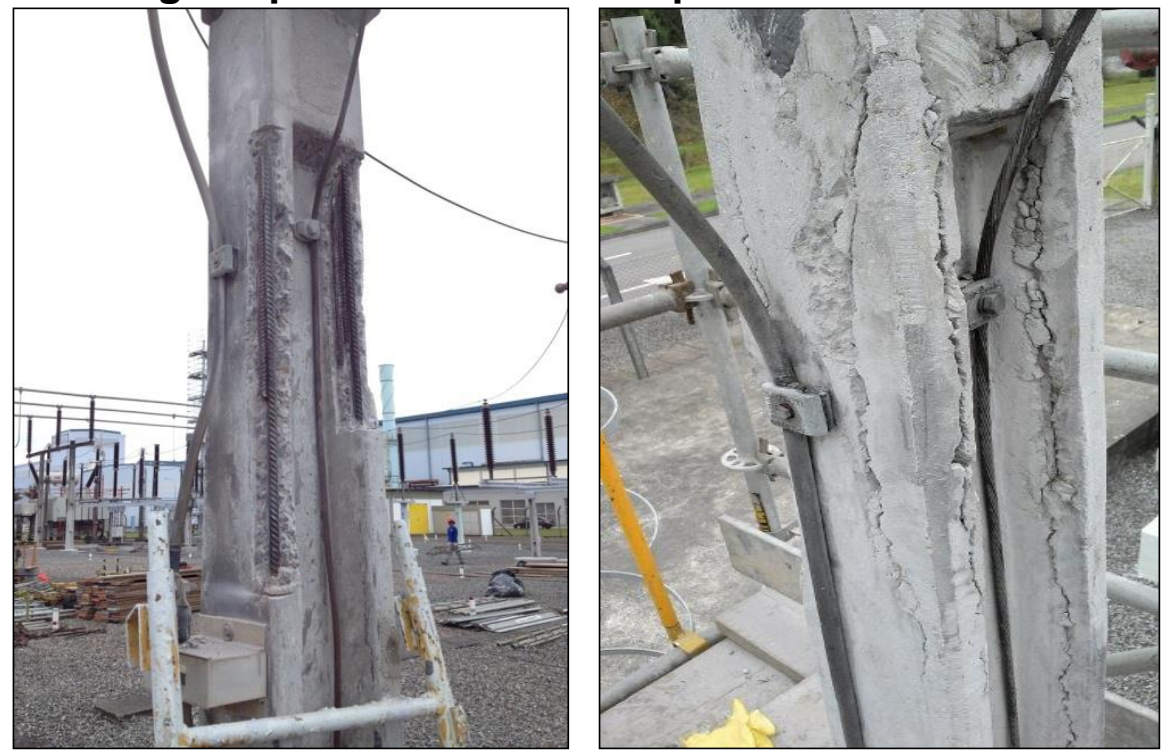

Figura 7: Estruturas avariadas aguardando reparo

Seguindo as premissas básicas, e todos os procedimentos definidos na fase de planejamento todas as estruturas de concreto da SE 230kV passaram por recuperação.
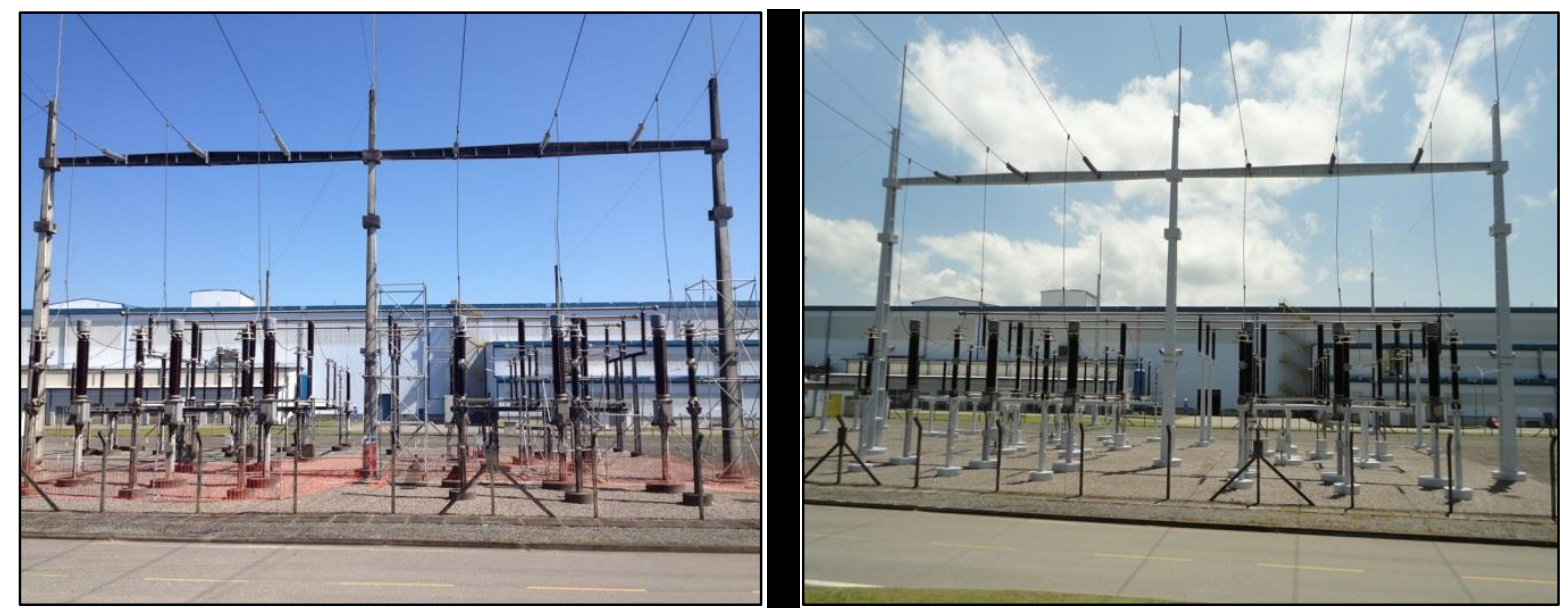

Figura 8: Antes e depois da Recuperação das Estruturas

\section{RESULTADOS E DISCUSSÃO}

Somando as horas de trabalho de todos os envolvidos neste serviço foram dedicadas 5.752 horas de trabalho atendendo a todos os procedimentos técnicos e normas de segurança sem ocorrências de incidentes graves.

No total, foram 96 dias corridos se dividindo em 75 dias com atividades e 21 dias de chuvas/folgas de trabalho. Ainda durante os 75 dias de trabalhados ocorreram interrupções parciais em 14 dias devidos a incidência de chuvas.

* Contribuição técnica ao $35^{\circ}$ Seminário de Balanços Energéticos Globais e Utilidades e $29^{\circ}$ Encontro de Produtores e Consumidores de Gases Industriais, 13 a 15 de agosto de 2014, São Paulo, SP, Brasil. 

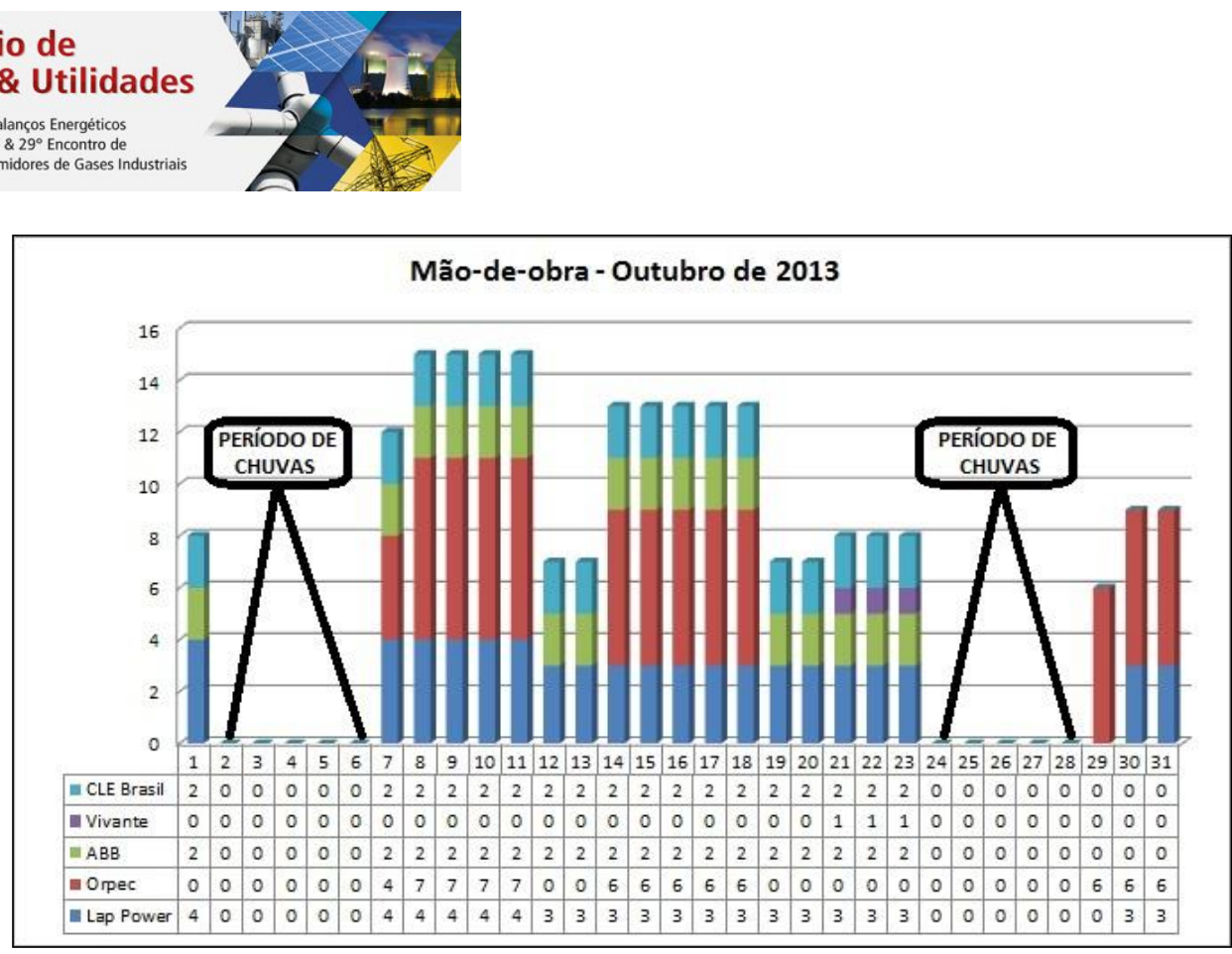

Figura 9: Controle de Horas do Mês de Outubro de 2013

As anomalias registradas apontam a evolução e envolvimento de toda a equipe, trabalhando focadamente na base da pirâmide de Frank Bird. Algumas anomalias foram consideradas graves, como falta de um talabarte do cinto de segurança ou choques de indução. Foi frequente a interrupção dos serviços para esclarecimentos e ajustes.

\begin{tabular}{|c|c|c|c|c|c|}
\hline 5030 & $\begin{array}{l}\text { Dois colaboradores nẫo realizaram teste de } \\
\text { PA e Alcoolemia, porém nẫo tinham } \\
\text { realizados trabalhos em altura. }\end{array}$ & $1110+2013$ & $\begin{array}{l}\text { Foram encaminhados imediatamente ao } \\
\text { ambulatório para reasizaçăo dos testes. }\end{array}$ & Orpec & TestePA \\
\hline 5034 & $\begin{array}{l}\text { Montando andaime por fora da estrutura } \\
\text { ficando muito próximo do limite de segurança } \\
\text { das linhas na SE230kV. }\end{array}$ & 15/10+2013 & \begin{tabular}{|l|} 
Foi orientado ao colaborador realizar a \\
montagem pela parte de dentro do andaime
\end{tabular} & Orpec & Riscos de Choque Elétrico \\
\hline 5073 & $\begin{array}{l}\text { Ao manusear uma prancha de madeira de } \\
\text { andaime, a mesma bateu contra uma tampa de } \\
\text { concreto e quebrou a tampa, que caiu sobre } \\
\text { os cabos de média tensấo. Sem aparentes } \\
\text { danos aos cabos. }\end{array}$ & 201112013 & $\begin{array}{l}\text { Foi realizado DDS sobre cuidados e riscos } \\
\text { referente a anomalia, será substituida a } \\
\text { tampa de concreto, e o local está } \\
\text { sinalizado com cones. }\end{array}$ & Orpec & Riscos de Acidentes \\
\hline
\end{tabular}

Figura 10. Tabela com registros de anomalias

As esquipes de montagem de andaimes apresentaram certa resistência em alguns pontos aonde havia a linha energizada, houve um intenso trabalho de esclarecimento para o entendimento de todos. Somente após a compreensão da equipe foi possível dar sequencia nas atividades.

Os trabalhos se iniciaram em 19/08/2013 e foram encerrados no dia 29/11/2013.

\section{CONCLUSÃo}

Após a limpeza das estruturas de concreto notou-se grande quantidade de trincas que futuramente poderiam comprometer a integridade operacional da Subestação e por isso foram realizados aditivos extras de aplicação de resina PU e Fibra de Carbono, elevando assim os custos para 33,78\% acima do valor inicial.

Além dos custos adicionais com terceiros, foram necessários mão de obra extra da CLE Brasil para o acompanhamento, contribuindo para a elevação dos custos iniciais do serviço.

O objetivo principal de recuperar todas as estruturas de concreto sem ocorrências de incidentes ou perturbações no fornecimento de energia elétrica foi alcançado. Esse

* Contribuição técnica ao $35^{\circ}$ Seminário de Balanços Energéticos Globais e Utilidades e $29^{\circ}$ Encontro de Produtores e Consumidores de Gases Industriais, 13 a 15 de agosto de 2014, São Paulo, SP, Brasil. 
sucesso foi conquistado devido ao grande empenho e comprometimento de todas as equipes envolvidas neste que é um serviço sem literaturas ou muitos casos para serem tomados como exemplo. Vale destacar a falta de literaturas para que servissem como base e apoio na realização deste tipo de atividade.

Assim, a subestação SE $230 \mathrm{kV}$ prolongou sua vida útil podendo garantir maior segurança as pessoas e ao sistema.

\section{Agradecimentos}

Agradeço ao apoio da diretoria que deu todo o subsidio e compreensão para o sucesso desta delicada manutenção e a todos os colegas de trabalhos envolvidos.

\section{REFERÊNCIAS}

1 NR, Norma Regulamentadora Ministério do Trabalho e Emprego. NR-10 - Segurança em Instalações e Serviços em Eletricidade. 2004.

2 NR, Norma Regulamentadora Ministério do Trabalho e Emprego. NR-35 - Trabalhos em Altura. 2012.

\section{BIBLIOGRAFIA}

1 ABNT, Associação Brasileira de Normas Técnicas. NBR-5410-Instalações Elétricas em Baixa Tensão. Rio de Janeiro ABNT, 2004.

2 ABNT, Associação Brasileira de Normas Técnicas. NBR-14039-Instalações Elétricas em Média Tensão. Rio de Janeiro ABNT, 2003. 